\title{
PHOTOCHEMICAL OZONE AND NITRIC OXIDE FORMATION IN AIR-NITROGEN DIOXIDE MIXTURES CONTAINING SULFUR DIOXIDE OR CHLORINE
}

\author{
JAMES S. WALLACE \\ Department of Mechanical Engineering, University of Toronto, \\ Toronto, Ontario, M5S 1A4, Canada \\ and \\ George S. SPringer ${ }^{*} \dagger$ and Donald H. Stedman + \\ + Department of Mechanical Engineering and $\ddagger$ Department of Chemistry, \\ The University of Michigan, Ann Arbor, MI 48109, U.S.A.
}

(First received 16 March 1979 and in final form 13 December 1979)

\begin{abstract}
Experiments were performed to investigate the effects of sulfur dioxide (0-10 ppm) and chlorine $(0-15 \mathrm{ppm})$ on ozone and nitric oxide concentrations in irradiated mixtures of nitrogen dioxide (1-5 ppm) and air. The mixtures were irradiated by ultraviolet fluorescent lamps while flowing at a steady speed through a $9 \mathrm{~m}$ long, $15.2 \mathrm{~cm}$ i.d. Pyrex tube. The presence of sulfur dioxide produced no measurable change in the ozone and nitric oxide concentrations. The addition of small quantities of chlorine increased the ozone concentration in much the same manner as the addition of a hydrocarbon. A reaction model was developed for the chlorine-nitrogen dioxide-air mixtures. The observed increase in ozone concentration could only be predicted if the following two reactions were included: $\mathrm{ClOO}+\mathrm{NO} \rightarrow \mathrm{NO}_{2}+\mathrm{ClO}$ and $\mathrm{ClOO}+\mathrm{NO} \rightarrow$ $\mathrm{ClNO}+\mathrm{O}_{2}$. Significant quantities of unexpected condensation nuclei were also observed in the chlorine-nitrogen dioxide-air mixtures.
\end{abstract}

\section{INTRODUCTION}

Ozone concentrations exceeding ambient levels were first observed in power plant plumes by Davis et al. (1974). This observation has since been amply confirmed by Miller et al. (1978) and by Keifer (1977). In both of these most recent reports it appears that nitrogen oxides and ambient hydrocarbons are responsible for the ozone formation. However, it has also been suggested (Davis et al., 1974) that reactions of sulfur dioxide and oxides of nitrogen may result in ozone formation. Although early work by Stephens et al. (1956) implied that sulfur dioxide reactions could not generate ozone, more recent studies by Altwicker (1976) indicate that such a possibility does indeed exist. We therefore studied the possibility that sulfur dioxide or chlorine released by burning coal might participate in the photochemical reactions which form ozone. The participation of chlorine in such reactions had previously been suggested by Pierrard (1969).

Several studies have been conducted with sulfur dioxide-nitrogen dioxide mixtures with data only reported for sulfur dioxide oxidation rates (Smith and Urone, 1974; Miller, 1977). Several other authors

* To whom correspondence should be addressed. considered the effect of sulfur dioxide on air and nitrogen dioxide mixtures containing hydrocarbons, without any strong effect being apparent (Ripperton et al. 1965; Altshuller et al. 1968 ; Wilson and Levy, 1970 and Wilson et al. 1972). The only previous experiment with mixtures of air-nitric oxide (instead of nitrogen dioxide), and chlorine was performed by Bittker and Wong (1978). Their results are not directly applicable to photochemical reactions near the earth's surface because they used a light spectrum characteristic of the stratosphere. Tests with chlorine-nitrogen dioxide-air mixtures containing hydrogen and formaldehyde have been performed by Niki et al. (1977) and by Hanst and Gay (1977) respectively. These investigators focused their attention on the spectroscopic identification of the reaction products.

The available data do not as yet explain adequately photochemical reactions in nitrogen dioxide-air mixtures containing either sulfur dioxide or chlorine. The main objective of this investigation was, therefore, to obtain data which will aid in understanding the reactions occurring in irradiated mixtures of sulfur dioxide-nitrogen dioxide-air and chlorine-nitrogen dioxide-air. To accomplish this objective, ozone and nitric oxide concentrations were measured in such mixtures under a wide range of experimental conditions. 


\section{EXPERIMENTAI}

The experiments were performed in a flow-type smog chamber described in detail by Shen et al. (1977)

The photochemical reactions took place in a $9 \mathrm{~m}$ long $15.2 \mathrm{~cm}$ i.d. horizontal Pyrex tube ("reaction vessel" - Fig. 1). Twelve openings were made on the top of the tube for inserting sampling probes. The first opening was $23 \mathrm{~cm}$ from the entrance of the tube. The distance between any two successive openings was $76 \mathrm{~cm}$. A stainless steel mixing chamber, containing stainless steel screen flow straighteners, was connected to the upstream end of the reaction vessel. The test gases were fed directly into this chamber. The downstream end of the tube vented at atmospheric pressure.

The UV radiation was produced by $48 \mathrm{~F} 40 \mathrm{BL}$ (Gencral Electric) fluorescent lamps placed around the reaction vessel symmetrically on a $31.7 \mathrm{~cm}$ dia. circle. The lamps were mounted on two semicircular metal shells covered on the inside with aluminum foil. Room air was blown through the annulus between the reaction vessel and the shell in the direction opposite to the flow inside the reaction vessel. The maximum temperature rise of the cooling air was $7^{\circ} \mathrm{C}$. The temperature rise of the gas-air mixture along the reaction vessel was always less than $4 \mathrm{C}$. The total light intensity was characterized by the photolysis frequency of nitrogen dioxide $k_{1}$ (Shen et al. 1977; Stedman and Niki, 1973). For the present apparatus $k_{1}$ was found to be $0.39 \mathrm{~min}^{-1}$. This value is a little over half the value at noon in the lower atmosphere at $40^{\circ} \mathrm{N}$ latitude.

Air used in the experiments was supplied from an airconditioned room by an oil-free, diaphragm type compressor. The air was passed through a series of drying agents and filters and was then branched into two streams. One stream was designated as "dry air", while the other stream passed through a humidifier where it was saturated with water vapor. The two streams were then joined together. The relative humidity of the test air was controlled at $50 \%$ by adjusting the flowrates of the two streams of air.

The nitrogen dioxide and sulfur dioxide were supplied prediluted in cylinders of nitrogen. The nitrogen dioxide, sulfur dioxide, and air flow rates were regulated by needle valves and measured by flow meters. Chlorine gas was metered directly into the mixing chamber with a Harvard Apparatus infusion pump.

The flow rates used in the experiments varied from $47 \mathrm{~cm}^{3}$ $\mathrm{s}^{-1} .753 \mathrm{~cm}^{3} \mathrm{~s}^{-1}$. The mean velocities corresponding to these flow rates were $0.259 \mathrm{~cm} \mathrm{~s}^{-1}$ and $4.13 \mathrm{~cm} \mathrm{~s}^{-1}$. The Reynolds number (based on diameter) thus ranged between 26 and 420 .

The sampling probes, described in detail by Wallace (1978), were connected to the measuring instruments with Teflon (for ozone), polypropylene (for nitric oxide) and Tygon (for particulates) lines. Losses in the sampling lines were assessed and were found to be negligible (Wallace, 1978). Ozone was measured with a chemiluminescent type ozone meter (McMillan Electronics Corporation Model 1100-3). Nitric oxide was measured with a chemiluminescent detector built in this laboratory. Both the ozone and the nitric oxide detectors were calibrated periodically. The concentration of condensation nuclei was measured with a type CN Small Particle Detector manufactured by Gardner Associates. Nitrogen dioxide concentrations were checked by measurement as NO after thermal decomposition.

The initial operation, "cleaning" the reaction vessel. was performed whenever a change was made from one test gas to another. The lighting system was energized and the reaction vessel was flushed with $50 \%$ relative humidity air until all measured ozone concentrations were less than $4 \mathrm{ppb}$, al measured nitric oxide concentrations were less than $10 \mathrm{ppb}$, and less than 200 condensation nuclei $\mathrm{cm}^{-3}$ sample were detected. Once these conditions were met, the air flow and nitrogen dioxide concentrations were adjusted to the desired value and data were taken. The test gas was then introduced and data were taken again. With sulfur dioxide, the measurements were made at two sulfur dioxide concentrations (I and $10 \mathrm{ppm}$ ) and also after the flow of sulfur dioxide was stopped. With chlorine the measurements were repeated at each chlorine concentration and also after the chlorine flow was stopped. Data were obtained for different initial concentrations of the nitrogen dioxide and the test gas, this concentration being denoted by the subscript zero. The term "initial concentration" refers to conditions at the inlet of the reaction vessel. Concentration measurements were made as a function of distance $Z$ along the vessel. This distance was converted to irradiation time $t$ by the expression $t=Z / V$ where $V$ was the mean flow velocity. The data were corrected for surface effects as described in the Appendix.

For further experimental details the reader is referred to Wallace (1978).

\section{REACTION MECHANISMS}

The reactions which occur in the nitrogen dioxide-air mixtures are well known (Stedman and Niki, 1973). For use in this experiment, however, the abbreviated mechanism shown in Table 1 was adequate. A more comprehensive model which included 12 additional reactions was also considered (Wallace, 1978). The differences in the ozone and nitric oxide concentrations predicted by this model and the simple one listed in Table 1 were less than the spread in the data. Hence, the mechanism shown in Table 1 was adopted.

A reaction mechanism for sulfur dioxide-nitrogen dioxide-air mixtures was proposed by Davis et al. (1974). This mechanism was later discussed and criti-

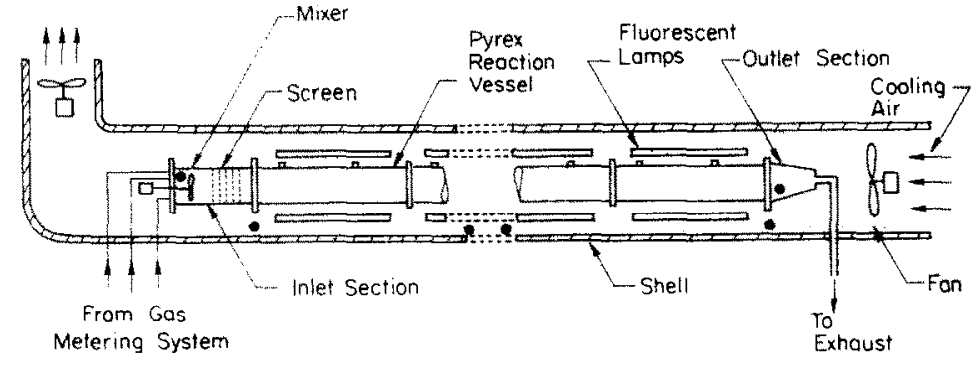

- Thermocouples

a. Somple Connections

Fig. 1. Schematic of experimental apparatus. 
Table 1. Reactions and rate constants used to model ozone formation in mixtures of nitrogen dioxide and air

\begin{tabular}{lll}
\multicolumn{1}{c}{ Reaction } & \multicolumn{1}{c}{ Rate constant $(a) 298 \mathrm{~K}$} & \multicolumn{1}{c}{ Reference } \\
\hline 1. $\mathrm{NO}_{2}+h v \rightarrow \mathrm{NO}+\mathrm{O}$ & $0.39 \mathrm{~min}^{-1}$ & This work \\
2. $\mathrm{O}+\mathrm{O}_{2}+\mathrm{M} \rightarrow \mathrm{O}_{3}+\mathrm{M}$ & $4.2 \times 10^{6} \mathrm{~min}^{-1 *}$ & Hampson and Garvin (1978) \\
3. $\mathrm{O}_{3}+\mathrm{NO} \rightarrow \mathrm{NO}_{2}+\mathrm{O}_{2}$ & $27.0 \mathrm{ppm}^{-1} \mathrm{~min}^{-1}$ & Hampson and Garvin (1978) \\
4. $\mathrm{O}+\mathrm{NO}_{2} \rightarrow \mathrm{NO}+\mathrm{O}_{2}$ & $1.37 \times 10^{4} \mathrm{ppm}^{-1} \mathrm{~min}^{-1}$ & Hampson and Garvin (1978) \\
\hline
\end{tabular}

* Pseudo first-order $\left(k_{2}^{\prime}=k_{2}\left[\mathrm{O}_{2}\right][\mathrm{M}]\right.$, where $\left.\left[\mathrm{O}_{2}\right]=2 \times 10^{5} \mathrm{ppm},[\mathrm{M}]=1 \times 10^{6} \mathrm{ppm}\right)$.

Table 2. Sulfur dioxide reaction mechanism

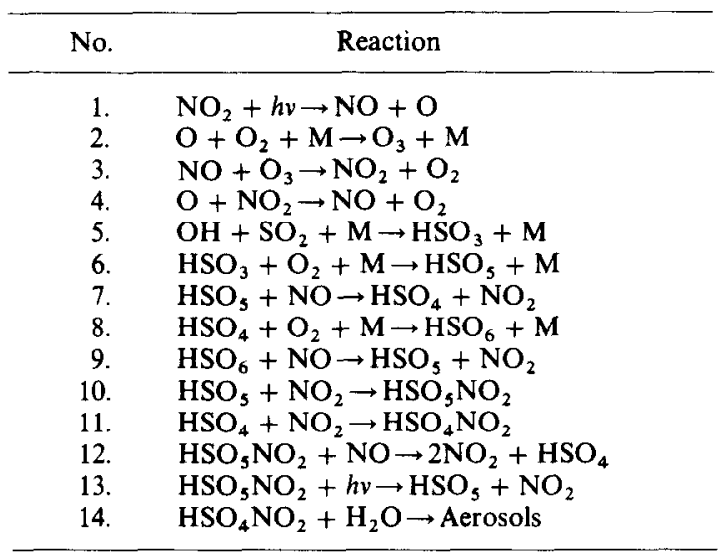

cized by Miller (1977) and by Bufalini and Walter (1977) (Table 2).

The reaction mechanism proposed for chlorine-nitrogen dioxide-air mixtures is listed in Table 3. This mechanism was formulated with the aim of providing estimates of the amounts of ozone and nitric oxide formed in chlorine-nitrogen dioxide-air mixtures and a qualitative description of the processes that occur. Therefore, the proposed mechanism includes only those reactions believed to be most significant.

Reactions 1-4 are required to account for ozone formation in mixtures of air and nitrogen dioxide only. Reactions 15-18 and 21-28 were selected from the chlorine reactions included in a survey by Watson (1977). Reaction 15 is the source of chlorine atoms (in an actual plume the source of chlorine atoms would be the reaction $\mathrm{OH}+\mathrm{HCl} \rightarrow \mathrm{Cl}+\mathrm{H}_{2} \mathrm{O}$ ). Reactions 19 and 20 were suggested by Pierrard (1969). Reaction 29, the loss of chlorine through reaction at the surface of the condensation nuclei, was added after the experiments showed that greater chlorine loss than could be accounted for by any gas phase process was observed along with the appearance of unexpected and unidentified particles. It should be noted that any heterogeneous chlorine loss mechanism, including atom loss at the walls, will show similar effects.

Ozone and nitric oxide concentrations were calculated as a function of irradiation time and initial mixture composition on the basis of the reactions included in Tables 1 and 3. To perform these calculations, conservation equations were formulated for the most important species in each mechanism. In forming the conservation equation for chlorine, it was postulated that the chlorine loss at the surface of the condensation nuclei was proportional to the total surface area of the condensation nuclei formed and to the instantaneous chlorine concentration $\left[\mathrm{Cl}_{2}\right]$ in the mixture

chlorine concentration

change per unit time

due to interaction

$$
=-k_{29} A_{N} N\left[\mathrm{Cl}_{2}\right]
$$

with nuclei,

where $k_{29}$ is a constant, $A_{N}$ is the surface area of a single condensation nuclei, and $N$ is the condensation nuclei concentration as a function of irradiation time. For the purposes of this calculation all of the condensation nuclei were assumed to have the same diameter, $2 \times$ $10^{-5} \mathrm{~cm}$. The concentration of nuclei as a function of time, $N$, was measured for each test mixture. The maximum concentration of nuclei observed varied from about $300,000 \mathrm{~cm}^{-3}$ for the mixture with $1.2 \mathrm{ppm}$ initial chlorine and nitrogen concentrations to greater than $10^{7} \mathrm{~cm}^{-3}$ for the mixture with a $1.2 \mathrm{ppm}$ initial nitrogen concentration and a $9.6 \mathrm{ppm}$ initial chlorine concentration.

The system of conservation equations for each of the two mechanisms listed in Tables 1 and 3 was solved using an algorithm by Gear (1971). The rate constants used in the calculations and the sources for these constants are included in Tables 1 and 3. When available, the rate constants recommended by Hampson and Garvin (1978) were used, although in scveral instances, e.g. $k_{17}$ and $k_{18}$, the value used represents the upper or lower limit of the recommended value (see footnotes for Table 3). The rate constant for reaction 1 was determined from data for irradiated mixtures of air and nitrogen dioxide only, as indicated previously. The rate constants for reactions 15,22 , and 25 (Table 3 ) were calculated from the value of $k_{1}$ (Wallace, 1978). Rate constants were not available for reactions 19,20 , or 29 . Reactions 19 and 20 are both possible reactions for the reactants $\mathrm{ClOO}$ and NO. Consideration of entropy and energy factors involved in the two reactions led to the suggestion that reaction 20 would proceed at a faster rate than reaction 19 (Wallace, 
Table 3. Reaction mechanism for irradiated mixtures of air, nitrogen dioxide and chlorine

\begin{tabular}{|c|c|c|}
\hline Reaction & $\begin{array}{l}\text { Rate constant } \\
\text { ppm }^{-1} \min ^{-1}\end{array}$ & Reference \\
\hline 1. $\mathrm{NO}_{2}+h w \rightarrow \mathrm{NO}+\mathrm{O}$ & $0.39 \mathrm{~min}^{-1}$ & This work \\
\hline 2. $\mathrm{O}+\mathrm{O}_{2}+\mathrm{M} \rightarrow \mathrm{O}_{3}+\mathrm{M}$ & $4.39 \times 10^{6} \min ^{-1}(1)$ & Hampson and Garvin (1978) \\
\hline 3. $\mathrm{O}_{3}+\mathrm{NO} \rightarrow \mathrm{NO}_{2}+\mathrm{O}_{2}$ & 27. & Hampson and Garvin (1978) \\
\hline 4. $\mathrm{O}+\mathrm{NO}_{2} \rightarrow \mathrm{NO}+\mathrm{O}_{2}$ & $1.37 \times 10^{4}$ & Hampson and Garvin (1978) \\
\hline 15. $\mathrm{Cl}_{2}+h v \rightarrow \mathrm{Cl}+\mathrm{Cl}$ & $0.05 \min ^{-1}(2)$ & Wallace (1978) \\
\hline 16. $\mathrm{Cl}+\mathrm{Cl}+\mathrm{M} \rightarrow \mathrm{Cl}_{2}+\mathrm{M}$ & $461.0(3)$ & Hampson and Garvin (1978) \\
\hline 17. $\mathrm{Cl}+\mathrm{O}_{2}+\mathrm{M} \rightarrow \mathrm{ClOO}+\mathrm{M}$ & $6 \times 10^{7} \min ^{-1}(4)$ & Hampson and Garvin (1978) \\
\hline 18. $\mathrm{ClOO}+\mathrm{M} \rightarrow \mathrm{Cl}+\mathrm{O}_{2}+\mathrm{M}$ & $4 \times 10^{7} \min ^{-1}(5)$ & Hampson and Garvin (1978) \\
\hline 19. $\mathrm{ClOO}+\mathrm{NO} \rightarrow \mathrm{ClO}+\mathrm{NO}_{2}$ & $4 \times 10^{3}$ & This work \\
\hline 20. $\mathrm{ClOO}+\mathrm{NO} \rightarrow \mathrm{ClNO}+\mathrm{O}_{2}$ & $4 \times 10^{4}$ & This work \\
\hline 21. $\mathrm{Cl}+\mathrm{NO}+\mathrm{M} \rightarrow \mathrm{ClNO}+\mathrm{M}$ & $3.8 \times 10^{3}(6)$ & Hampson and Garvin (1978) \\
\hline 22. $\mathrm{CNO}+h v \rightarrow \mathrm{Cl}+\mathrm{NO}$ & $0.08 \mathrm{~min}^{-1}(7)$ & Wallace $(1978)$ \\
\hline 23. $\mathrm{Cl}+\mathrm{ClNO} \rightarrow \mathrm{NO}+\mathrm{Cl}_{2}$ & $4.5 \times 10^{4}$ & Hampson and Garvin (1978) \\
\hline 24. $\mathrm{Cl}+\mathrm{NO}_{2}+\mathrm{M} \rightarrow \mathrm{ClNO}_{2}+\mathrm{M}$ & $1.35 \times 10^{4}(8)$ & Hampson and Garvin (1978) \\
\hline 25. $\mathrm{ClNO}_{2}+h \nu \rightarrow \mathrm{Cl}+\mathrm{NO}_{2}$ & $0.010 \min ^{-1}(9)$ & Wallace (1978) \\
\hline 26. $\mathrm{Cl}+\mathrm{CINO}_{2} \rightarrow \mathrm{Cl}_{2}+\mathrm{NO}_{2}$ & $45.0(10)$ & Hampson and Garvin (1978) \\
\hline 27. $\mathrm{Cl}+\mathrm{O}_{3} \rightarrow \mathrm{ClO}+\mathrm{O}_{2}$ & $1.7 \times 10^{4}$ & Hampson and Garvin (1978) \\
\hline 28. $\mathrm{ClO}+\mathrm{NO} \rightarrow \mathrm{Cl}+\mathrm{NO}_{2}$ & $2.9 \times 10^{4}$ & Hampson and Garvin (1978) \\
\hline 29. $\mathrm{Cl}_{2} \stackrel{\text { particles }}{\longrightarrow}$ products & $516 \mathrm{~cm} \mathrm{~min}^{-1}$ & This work \\
\hline
\end{tabular}

(1) The value given is the product $k_{2}\left[\mathrm{O}_{2}\right][\mathrm{M}]$, where $\left[\mathrm{O}_{2}\right]=2 \times 10^{5} \mathrm{ppm},[\mathrm{M}]=1 \times 10^{6} \mathrm{ppm}$, and $k_{2}$ is from Hampson and Garvin (1978).

(2) $k_{15}$ defined by $\mathrm{d}\left[\mathrm{Cl}_{2}\right] \mathrm{d} t=-k_{15}\left[\mathrm{Cl}_{2}\right]$ was calculated using the value of $k_{1}$, the absorption cross sections for $\mathrm{NO}_{2}$ and $\mathrm{Cl}_{2}$, and the relative spectral energy distribution measured inside the reaction vessel (Wallace, 1978).

(3) The value given here is the product $k_{16}[\mathrm{M}]$, where $[\mathrm{M}]=1 \times 10^{6} \mathrm{ppm}$ and $k_{16}$ was taken from Hampson and Garvin (1978).

(4) The value given here is the product $k_{17}\left[\mathrm{O}_{2}\right][\mathrm{M}]$, where $\left[\mathrm{O}_{2}\right]=2 \times 10^{5} \mathrm{ppm}$ and $[\mathrm{M}]=1 \times 10^{6}$ The value of $k_{1}$, used was 4.7 times higher than the value recommended by Hampson and Garvin (1978). This value and the value of $k_{18}$ used are within the factor of ten uncertainty specified for the ratio $k_{17} / k_{18}$.

(5) The value given here is the product $k_{18}[\mathrm{M}]$, where $[\mathrm{M}]=1 \times 10^{6} \mathrm{ppm}$. The value of $k_{18}$ used was $40 \%$ less than the value recommended by Hampson and Garvin (1978). This value and the value of $k_{17}$ used are within the factor of ten uncertainty specified for the ratio $k_{17} / k_{18}$.

(6) The value given here is the product $k_{21}[\mathrm{M}]$, where $[\mathrm{M}]=1 \times 10^{6} \mathrm{ppm}$.

(7) Calculated using value of $k_{1}$, the absorption cross sections for $\mathrm{NO}_{2}$ and $\mathrm{ClNO}$, and the relative spectral energy distribution measured inside the reaction vessel (Wallace, 1978).

(8) The value given here is the product $k_{24}[\mathrm{M}]$, where $[\mathrm{M}]=1 \times 10^{6} \mathrm{ppm}$ and $k_{24}$ is the lower limit of the range of values given by Hampson and Garvin (1978).

(9) Calculated using the value of $k_{1}$, the absorption cross sections for $\mathrm{NO}_{2}$ and $\mathrm{CINO}_{2}$, and the relative spectra energy distribution measured inside the reaction vessel (Wallace, 1978).

(10) Lowest value given by Hampson and Garvin (1978).

1978). Therefore, reaction 20 was assigned the fastest rate constant possible, i.e. the biomolecular collision rate between $\mathrm{ClOO}$ and $\mathrm{NO}$ molecules. The bimolecular collision rate is generally between $1.5 \times 10^{5}$ and $1.5 \times 10^{4} \mathrm{ppm}^{-1} \mathrm{~min}^{-1}$. An intermediate value was chosen, resulting in $k_{20}=4 \times 10^{4} \mathrm{ppm}^{-1} \mathrm{~min}^{-1}$. Rate constants for reactions 19 and 29 were determined by matching the model to the data. To accomplish this, values were assumed for $k_{19}$ and $k_{29}$. The conservation equations representing the reaction mechanism in Table 3 were then solved for the different test mixtures. The ozone and nitric oxide concentrations predicted by these solutions were compared with the measured ozone and nitric oxide concentrations. The values chosen for $k_{19}$ and $k_{29}$ were adjusted and the process was repeated until the best agreement between the predicted and measured concentrations was obtained.

\section{RESULTS}

\section{Sulfur dioxide-nitrogen dioxide-air mixtures}

The sulfur dioxide concentration in power plant plumes may range from as much as $700 \mathrm{ppm}$ at the stack to less than $0.5 \mathrm{ppm}$ at distances greater than $25 \mathrm{~km}$. However, ozone formation has only been observed at distances greater than $24 \mathrm{~km}$ from the stack, where the sulfur dioxide concentration is low (Davis et al. 1974; Keifer, 1977). The sulfur dioxide concentrations selected for the tests were chosen to be representative of the sulfur dioxide concentrations present in the plume when the ozone is forming. Therefore, tests were performed with initial sulfur dioxide concentrations of 1 and $10 \mathrm{ppm}$. Each of these sulfur dioxide concentrations were tested in nitrogen dioxide-air mixtures with either 1 or $5 \mathrm{ppm}$ initial 
nitrogen dioxide concentrations. The temperature in the reaction vessel was maintained between $26-31^{\circ} \mathrm{C}$. These temperatures are similar to the temperatures in those regions of the plume where ozone formation was observed (Keifer, 1977).

In order to determine whether or not sulfur dioxide had any effect on the ozone and nitric oxide concentrations these concentrations were measured in air-nitrogen dioxide mixtures both with and without sulfur dioxide. For the range of concentrations tested ( 1 and $10 \mathrm{ppm}$ sulfur dioxide), the addition of sulfur dioxide to the nitrogen dioxide-air mixtures resulted in no measurable change in the amounts of ozone and nitric oxide formed. This result is illustrated in Fig. 2, where the data are presented. The ozone and nitric oxide concentrations calculated by the reaction mechanism postulated for nitrogen dioxide-air mixtures (no sulfur dioxide - Table 1) are also shown. The measured concentrations correlate well with the calculated ones indicating further that sulfur dioxide does not participate significantly in the photochemical reactions. These observations suggest that reactions 6-14 (Table 2) are either inappropriate or occur so slowly as to be insignificant. Unfortunately the rate constants for reactions 6-14 are largely unknown. Hence the contributions of these reactions could not be evaluated quantitatively. Since the addition of either 1 or $10 \mathrm{ppm}$ sulfur dioxide did not affect measurably the ozone and nitric oxide concentrations, it appears that sulfur dioxide was not responsible for the ozone formation observed in power plant plumes.
In order for ozone to form in sulfur dioxide-nitrogen oxides-air mixtures by means of the suggested reaction mechanism, hydroxyl radicals $(\mathrm{OH})$ must be present (reaction 5, Table 2). Thus, the hydroxyl radical concentration in the reaction vessel had to be evaluated. The hydroxyl radical concentration could not be measured directly but was inferred from ozone and nitric oxide measurements made in irradiated nitrogen dioxide-air mixtures containing carbon monoxide. These measurements, together with the results of a reaction model, indicated that the hydroxyl radical concentration in the reaction vessel was between $1.5-6.5 \times 10^{-8} \mathrm{ppm}$ (Wallace, 1978). This is of the same order of magnitude as $\mathrm{OH}$ concentrations observed in the atmosphere (Wang et al. 1975; Davis et al. 1976). Thus, hydroxyl radicals were evidently present in the reaction vessel in sufficient quantities to ensure the formation of ozone.

\section{Chlorine-nitrogen dioxide-air mixtures}

Chlorine released from burning coal is converted to hydrogen chloride during combustion (Stedman et al. 1974). In the power plant plume the hydrogen chloride reacts with hydroxyl radicals to form chlorine atoms. It is these chlorine atoms that are presumed to contribute to ozone formation through a chain of reactions (15-29 Table 3) involving chlorine and nitrogen-containing substances. This chain of reactions, beginning with the chlorine atoms, was examined in the present experiments in which chlorine gas was introduced into irradiated mixtures of air and
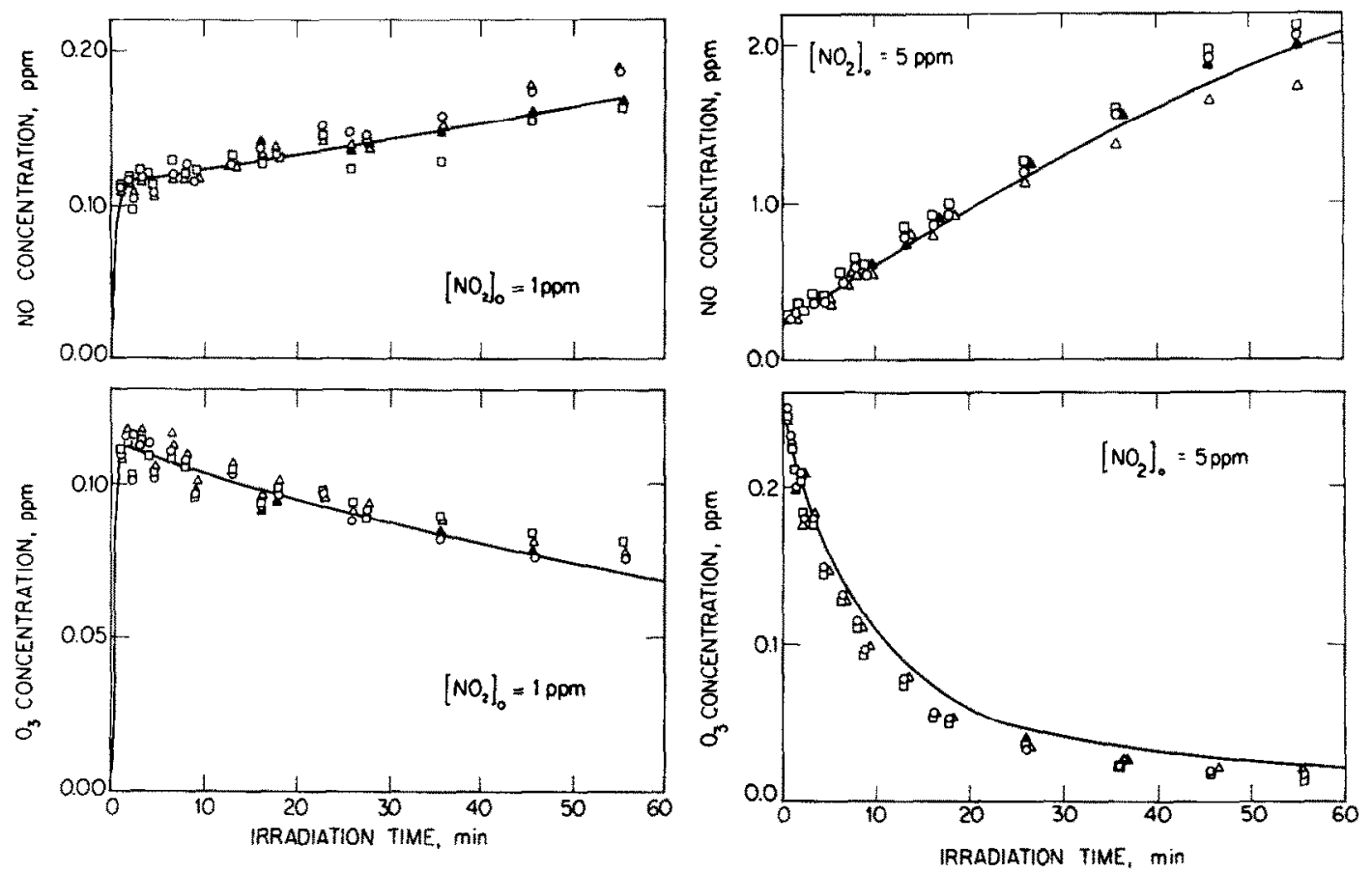

Fig. 2. Ozone and nitric oxide concentrations in irradiated sulfur dioxide-nitrogen dioxide-air mixtures. Data: $O-1 \mathrm{ppm}$ initial $\mathrm{SO}_{2}$ concentration, $\square-10 \mathrm{ppm}$ initial $\mathrm{SO}_{2}$ concentration, triangles are for nitrogen dioxide-air mixtures only: $\triangle$-before $\mathrm{SO}_{2}$ addition; $\Delta-$ after $\mathrm{SO}_{2}$ flow stopped. Solid lines are calculated concentrations for the nitrogen dioxide-air mixture. 
nitrogen dioxide. The chlorine gas readily photodissociated in the ultraviolet light present in the reaction vessel to form chlorine atoms.

Ozone, nitric oxide and condensation nuclei concentrations were measured as a function of irradiation time for each of fifteen mixtures indicated in Figs 3-5. The results are shown in these figures where the circles represent measurements taken with chlorine present in the mixture. The open triangles indicate concentrations measured in the mixture of air and nitrogen dioxide only, prior to the introduction of the chlorine. The solid triangles are for concentrations obtained after the chlorine flow was stopped (mix tures of air and $\mathrm{NO}_{2}$ only).

Ozone and nitric oxide concentrations calculated from the reaction mechanism proposed in Table 3 are shown in Figs 3-5 as dashed lines. For comparison, the ozone and nitric oxide concentrations calculated for mixtures of air and nitrogen dioxide only are also included in these figures (solid lines). For the tests with mixtures initially containing $1.2 \mathrm{ppm} \mathrm{NO} \mathrm{NO}_{2}$ (Fig. 3), the predicted ozone and nitric oxide concentrations show excellent agreement with the measured ozone and nitric oxide concentrations for all of the initial chlorine concentrations tested. The agreement between the predicted and measured ozone and nitric oxide concentrations becomes slightly worse as the initial $\mathrm{NO}_{2}$ concentration is increased. This may be observed in Fig. 5 (mixtures initially containing $5.4 \mathrm{ppm} \quad \mathrm{NO}_{2}$ ) where the agreement is reasonable for low chlorine concentrations but shows significant deviation at higher chlorine concentrations. The overprediction of ozone and the underprediction of nitric oxide suggests that the proposed reaction mechanism does not remove chlorine rapidly enough at high $\mathrm{NO}_{2}$ concentrations. Overall, however, the reaction mechanism proposed in Table 3 appears to be a reasonable representation of the processes which govern ozone formation in irradiated mix tures of chlorine-nitrogen dioxide-air, and provides reasonable estimates of the concentrations of ozone and nitric oxide formed in such mixtures.

The experimental evidence indicates that the addition of small quantities of chlorine to irradiated mixtures of air and nitrogen dioxide increases the ozone concentration in much the same manner as the addition of a hydrocarbon. It is emphasized, however, that in order to describe the observed ozone formation reaction 19 must be included in the reaction model. Without this reaction the observed increase in ozone concentration could not be predicted. Reaction 19 is mainly responsible for the ozone increase, but since reaction 20 occurs simultaneously and is probably faster, it was included as well. The absolute reaction rates which were needed in our model for reactions 19 and $20\left(4 \times 10^{3}\right.$ and $4 \times$ $10^{4} \mathrm{ppm}^{-1} \mathrm{~min}^{-1}$ ) indicate that these reactions cannot be neglected in future studies.

Infrared spectroscopic analyses were performed on chlorine-nitrogen dioxide -hydrogen-air mixtures by Niki et al. (1977) and on chlorine-nitrogen dioxide formaldehyde-air mixtures by Hanst and Gay (1977).
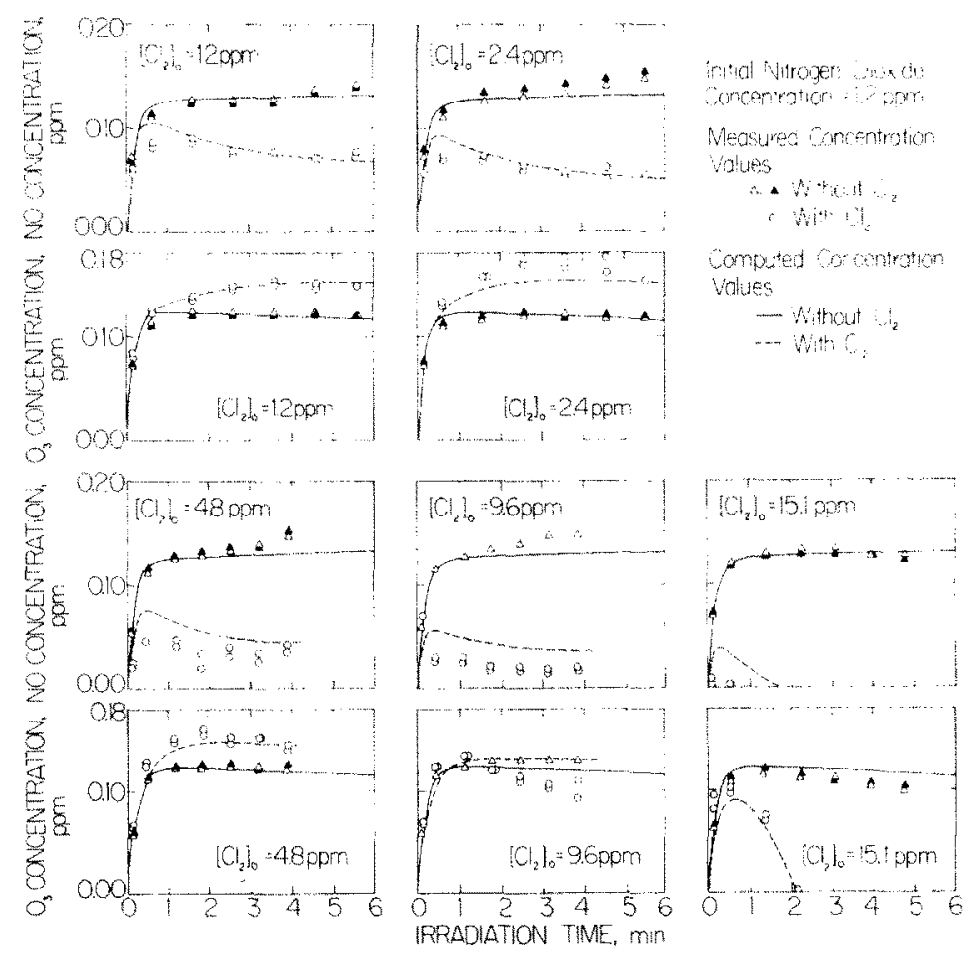

Fig. 3. Ozone and nitric oxide concentrations in irradiated chlorine-nitrogen dioxide-air mixtures. 
Niki et al. (1977) observed the formation of CINO in a mixture originally containing $21 \mathrm{ppm} \mathrm{Cl}_{2}, 10.7 \mathrm{ppm}$ $\mathrm{NO}_{2}$ and $14.3 \mathrm{ppm} \mathrm{H}_{2}$. After $5 \mathrm{~min}$ irradiation, the ratio $\left[\mathrm{CINO}_{2}\right] /[\mathrm{CINO}]$ measured by $\mathrm{Niki}$ and his coworkers was about 9 . Using the model in Table 3, we computed the ratio of $\left[\mathrm{CINO}_{2}\right] /[\mathrm{CINO}]$ for air initially containing $5.4 \mathrm{ppm} \mathrm{NO}_{2}$ and $15.1 \mathrm{ppm} \mathrm{Cl}_{2}$. After 5 min irradiation time, this calculation yielded the value of 10 for the $\left[\mathrm{CINO}_{2}\right] /[\mathrm{CINO}]$ ratio. The good agreement between the $\left[\mathrm{CINO}_{2}\right] /[\mathrm{CINO}]$ ratio given by Niki et al. (1977) and by the present model further supports the model described in Table 3.

During the preparation of this paper the work of Wongdontri-Stuper et al. (1978) was published, confirming the occurrence of reactions 19 and 20 . However, they found the product $k_{19} K_{17.18}$ to be $(5.6 \pm 2.3) \times$ $10^{-4} \mathrm{ppm}^{-2} \mathrm{~min}^{-1}$ and $k_{20} K_{17.18}$ to be $(6.0 \pm 3.8) \times$ $10^{-3} \mathrm{ppm}^{-2} \mathrm{~min}^{-1}$ as compared with values of $3 \times$ $10^{-2} \mathrm{ppm}^{-2} \mathrm{~min}^{-1}$ and $3 \times 10^{-1} \mathrm{ppm}^{-2} \mathrm{~min}^{-1}$ determined in this work. Thus, the values used here are about 50 times those of Wongdontri-Stuper et al. It should be pointed out that concentrations tested by Wongdontri-Stuper et al. were considerably higher than those used in the present work (example: $35 \mathrm{ppm}$ NO, $0.52 \% \mathrm{Cl}_{2}$ ). These higher concentrations, in conjunction with a photolysis rate for chlorine only slightly smaller $\left(k_{15}=0.018\right.$ vs $\left.0.05 \mathrm{~min}^{-1}\right)$, results in considerably higher concentrations of $\mathrm{Cl}$ and $\mathrm{ClOO}$. Thus, the rates of reactions 19 and 20 have a stronger influence on the results of their experiment. It is interesting to note, however, that they found the ratio $k_{20} / k_{19}$ to be $11.0 \pm 2.2$ compared with the value of 10.0 determined in this experiment.

The recent work of Spence et al. (1978) shows that chlorine atoms attack unreactive species such as methane and carbon monoxide which could be present in our charcoal filtered air supply. Wongdontri-Stuperet al. (1978) also recognized this possibility and suggested the oxidation of $\mathrm{NO}$ by the sequence,

$$
\begin{aligned}
\mathrm{Cl}+\mathrm{RH} & \rightarrow \mathrm{HCl}+\mathrm{R} \\
\mathrm{R}+\mathrm{O}_{2} & \rightarrow \mathrm{RO}_{2} \\
\mathrm{RO}_{2}+\mathrm{NO} & \rightarrow \mathrm{RO}+\mathrm{NO}_{2} \\
\mathrm{RO}+\mathrm{NO} & \rightarrow \mathrm{RONO}
\end{aligned}
$$

In the present experiment the reaction

$$
\mathrm{RO}+\mathrm{NO}_{2} \rightarrow \mathrm{RONO}_{2}
$$

would also have to be included as the concentration of $\mathrm{NO}_{2}$ is greater than that of NO. To determine whether or not this mechanism contributed to the observed ozone formation, the hydrocarbon concentrations present in the air supply were measured with a gas chromatograph. The methane concentration was found to be $1.6 \mathrm{ppm}$ and the $\mathrm{CO}$ concentration about $0.4 \mathrm{ppm}$ which demonstrates that the air supply was not contaminated by combustion derived hydrocarbons. Higher hydrocarbons could not be detected at the $0.1 \mathrm{ppm}$ level, as might be expected from the low $\mathrm{CO}$ reading. Assuming a steady-state for $\mathrm{RO}_{2}$, the rate of reaction 32 is given by

$$
\text { Rate }(32)=k_{30}[\mathrm{Cl}] /[\mathrm{RH}]
$$
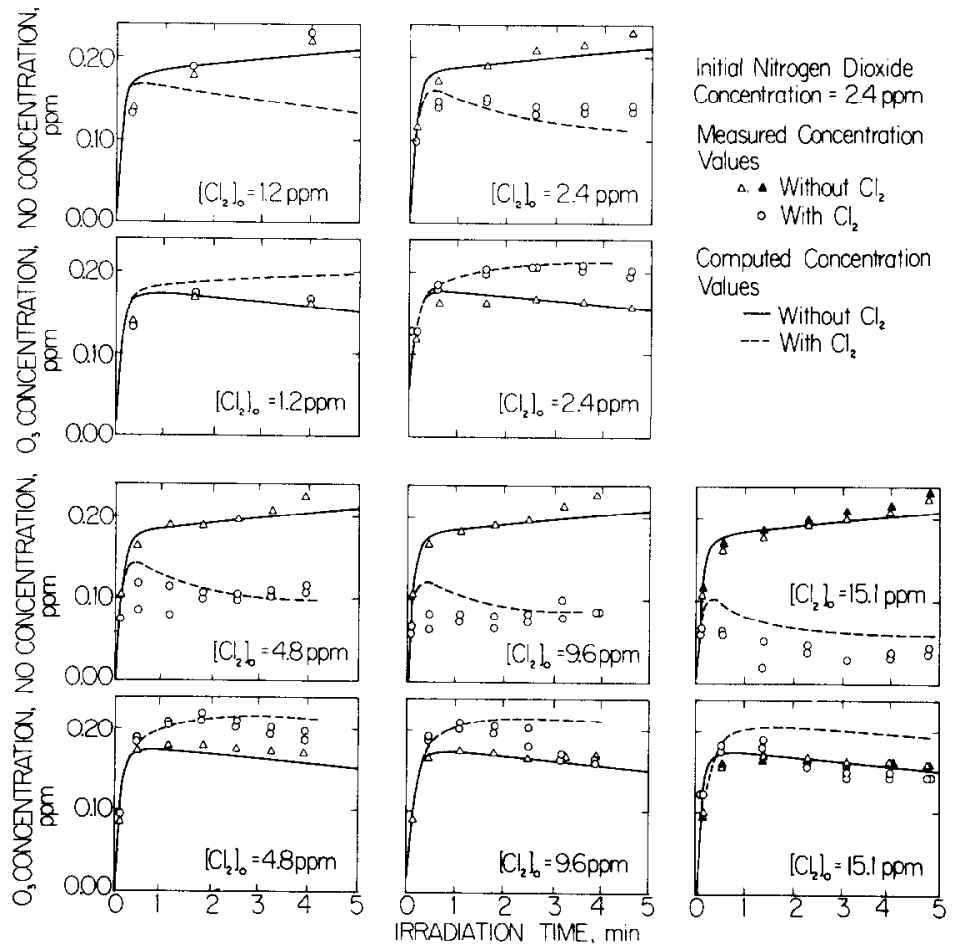

Fig. 4. Ozone and nitric oxide concentrations in irradiated chlorine-nitrogen dioxide-air mixtures. 


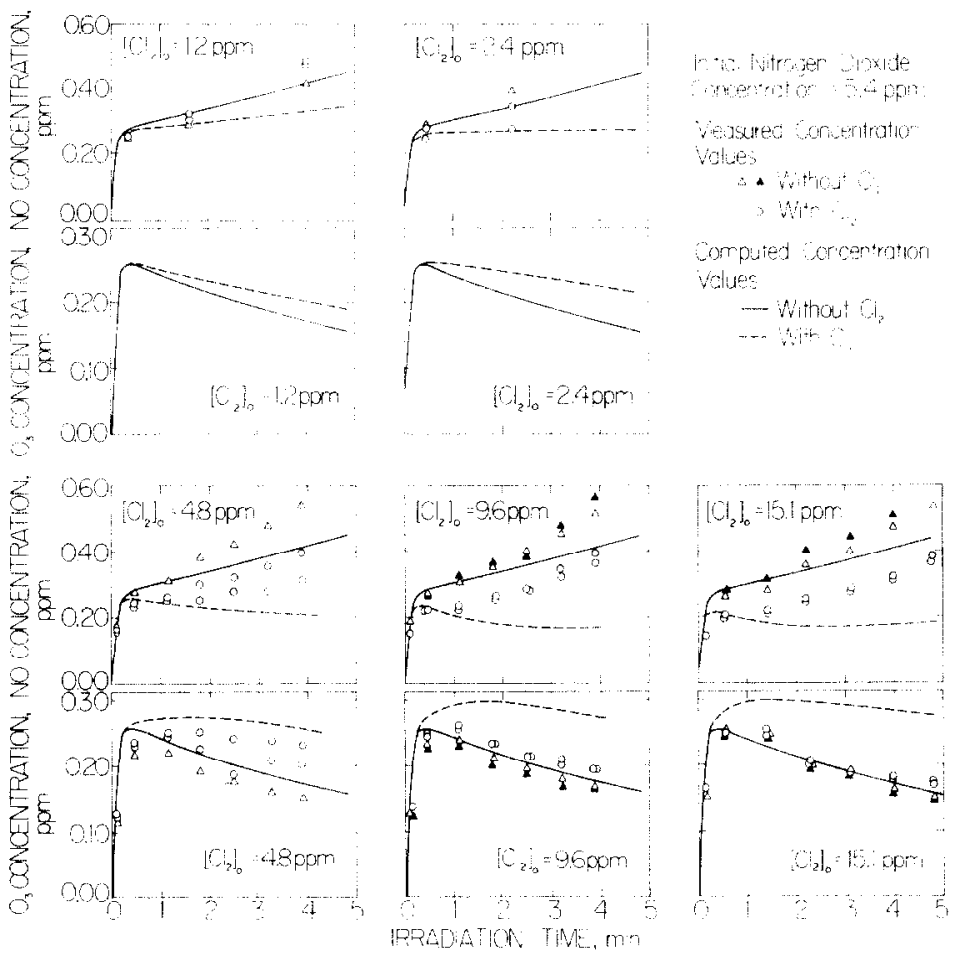

Fig. 5. Ozone and nitric oxide concentrations in irradiated chlorine-nitrogen dioxide-air mixtures.

This rate must be compared with the sum of the rates of reactions 19 and 20

$$
\operatorname{Rate}(19+20)=\left(k_{19}+k_{20}\right)[\mathrm{ClOO}] /[\mathrm{NO}]
$$

This was done for the mixture containing $1.2 \mathrm{ppm}$ $\mathrm{NO}_{2}$ and $4.8 \mathrm{ppm} \mathrm{Cl}_{2}$, a typical run shown in Fig. 3 . Using concentrations of $\mathrm{Cl}, \mathrm{ClOO}$, and $\mathrm{NO}$ computed for this test mixture by the model in Table 3 , the rate for reaction 30 was found to be $4.6 \times 10^{-3} \mathrm{ppm} \mathrm{min}^{-1}$ after $1 \mathrm{~min}$ of irradiation compared with $8.25 \times$

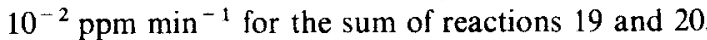
After $4 \mathrm{~min}$ irradiation, these values are $1.7 \times$

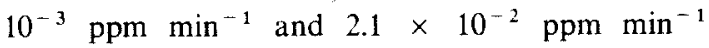
respectively. Thus, the rate of consumption of NO by

* Note added: Since this paper was completed and submitted for publication, a new value of the equilibrium constant $k_{17} / k_{18}$ has been published (Chemical Kinetic and Photochemical Data for Use in Stratospheric Modeling, JPL Publication 79-27). The new value is $3.7 \times 10^{-28} \times T$ $\times \exp (3217 / T) \mathrm{cm}^{3}$ molecule ${ }^{-1}$ or $1.26 \times 10^{-7} \mathrm{ppm}^{-1}$ at $300 \mathrm{~K}$. The value used in the present work is $7.5 \times$ $10^{\circ} \mathrm{ppm}{ }^{1}$. If the new equilibrium constant is indeed correct, then a mechanism other than the one proposed in Table 3 would be needed to account for the observed ozone formation. It has been suggested by one of the reviewers that, despite our best efforts, there may have been some hydrocarbons present in the air supply which could have contributed to the observed ozone formation. Thus, individuals conducting future experiments along these lines must be even more careful to eliminate all hydrocarbons from their experimental system. reaction 32 is about an order of magnitude less than by reactions 19 and 20 . The rate of loss of NO by reactions 33 and 34 is even smaller. Therefore, the presence of this small amount of methane could have increased the ozone concentration slightly but cannot account for the entire increase observed.

While the reactions of chlorine atoms with methane and carbon monoxide did not have a significant effect in the present experiments, chlorine in actual power plant plumes could be important in activating these otherwise inactive species. In any case, we believe that both reactions (19) and (20) ought to be considered as possible steps in the atmospheric fate of $\mathrm{CIOO}$.*

The role of the condensation nuclei must also be discussed. The results obtained imply that chlorine is lost rapidly somewhere. This loss must be taken into account as was done here by including reaction (29) in the reaction mechanism. It is interesting to note that Bittker and Wong (1978) observed a loss of chlorine in their system. In the absence of condensation nuclei measurements they attributed this to atomic chlorine loss at the surface of their chamber, as may also be true in this experiment. However, we should point out that the nature of the species involved in nuclei formation in these mixtures remains unknown.

Finally, the measured condensation nuclei concentrations were correlated with the initial nitrogen dioxide and initial chlorine concentrations according to the method proposed by Shen and Springer (1977) who suggested that the maximum concentration of condensation nuclei $N_{\max }$ formed in irradiated mix- 


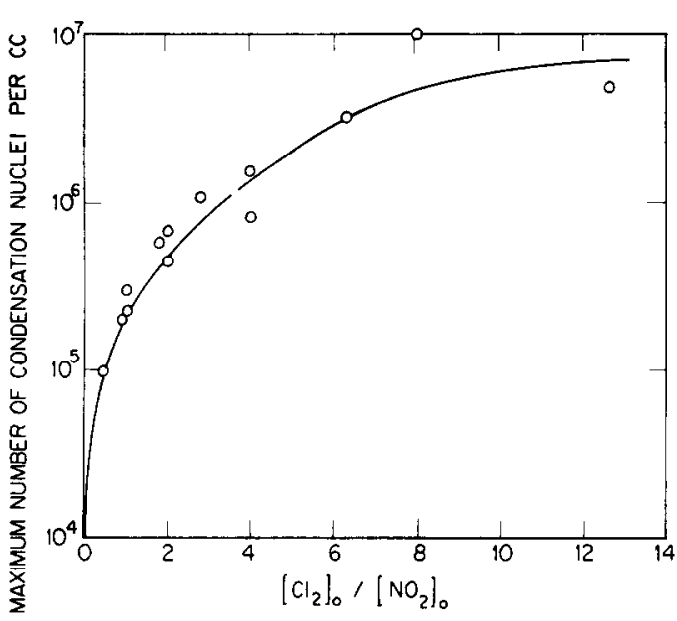

Fig. 6. Maximum condensation nuclei concentrations ohserved in chlorine-nitrogen dioxide-air mixtures as a function of the ratio of the initial chlorine concentration to the initial nitrogen dioxide concentration. $O$ data;- fit to data.

tures of air containing two reacting gases depends on the ratio of the initial concentrations of the two reacting gases $[\mathrm{A}]_{0}$ and $[\mathrm{B}]_{0}$

$$
\mathrm{N} \sim[\mathrm{A}]_{0} /[\mathrm{B}]_{0} .
$$

To test this hypothesis, $N_{\max }$ was plotted as a function of the ratio of the initial chlorine concentration to the initial nitrogen dioxide concentration $\left[\mathrm{Cl}_{2}\right]_{0} /\left[\mathrm{NO}_{2}\right]_{0}$. The results, displayed in Fig. 6, show excellent correlation between the maximum nuclei concentration and the initial concentration ratio lending support to Shen and Springer's hypothesis (Equation (4)).

In conclusion, the experimental evidence indicates that the addition of small quantities of chlorine to irradiated mixtures of air and nitrogen dioxide gives rise to ozone formation, and to the formation of large numbers of condensation nuclei. The ozone formation was considered to result from a mechanism involving only chlorine species; however, hydrocarbon involvement cannot be completely ruled out. It is important to note that while the generation of condensation nuclei correlates well with the ratio of the initial chlorine and initial nitrogen dioxide concentrations, the exact nature of these particles remains unknown.

\section{REFERENCES}

Altshuller A. P., Kopczynski S. L., Lonneman W. A., Becker T. L. and Wilson D. L. (1968) Photooxidation of propylene with nitrogen dioxide in the presence of sulfur dioxide. Envir. Sci. Technol. 2, 696-698.

Altwicker E. R. (1976) Ozone formation during sulfur dioxide irradiation. J. envir. Sci. Health A11, 439-443.

Bittker D. A. and Wong E. L. (1978) Effect of nitric oxide on photochemical ozone formation in mixtures of air with molecular chlorine and with trichlorofluoromethane. NASA Technical Paper 1192, Lewis Research Center, Cleveland, Ohio.

Bufalini J. J. and Walter T. A. (1977) Ozone formation from $\mathrm{SO}_{2}-\mathrm{NO}_{x}$ reactions. Presented at the 173 rd National ACS Meeting, New Orleans, Louisiana, U.S.A.

Davis D. D., Smith G. and Klauber G. (1974) Trace gas
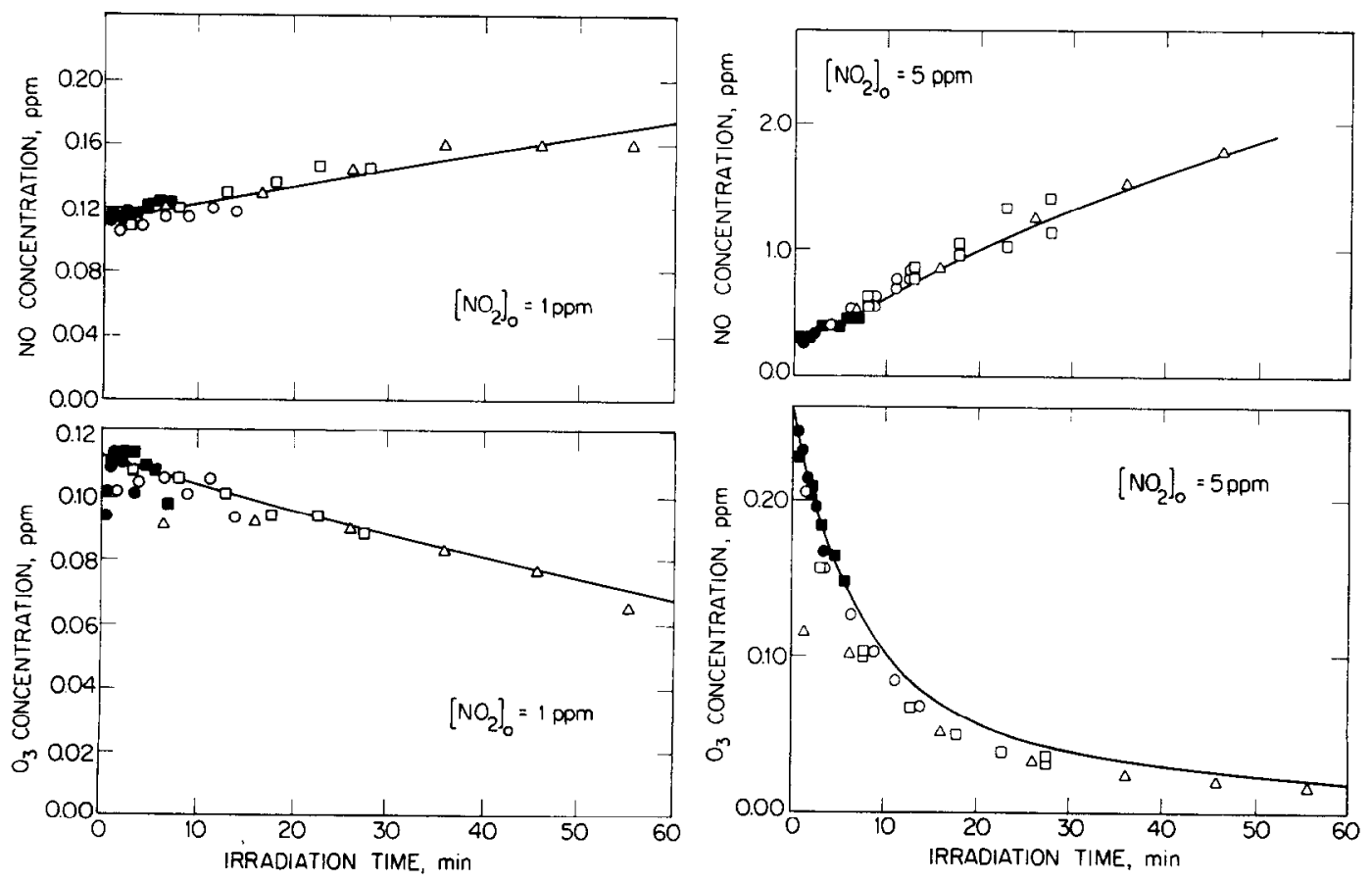

Fig. 7. Ozone and nitric oxide concentrations in irradiated nitrogen dioxide-air mixtures. Flow rates, $\mathrm{cm}^{3}$ $\mathrm{s}^{-1}: \Delta-47.2, \square-94.4, \bigcirc-188.8, \square-377.6,-755.1$. The solid lines are calculated concentrations for the reactions in Table 1. 
analysis of power plant plumes via aircraft measurements : $\mathrm{O}_{3}, \mathrm{NO}_{x}$, and $\mathrm{SO}_{2}$ chemistry. Science, N.Y. 186, 733- 736 .

Davis D. D., McGee T. J. and Heaps W. (1976) Direct tropospheric $\mathrm{OH}$ radical measurements via an aircraft platform: Laser induced fluorescence. Presented at the 12th Intl Symp. on Free Radicals, Laguna Beach, California, U.S.A.

Gay B. W., Jr. and Bufalini J. J. (1971) Nitric acid and the nitrogen balance of irradiated hydrocarbons in the presence of oxides of nitrogen. Envir. Sci. Technol 5, 422-425.

Gear C. W. (1971) The automatic integration of ordinary differential equations. Commun. Ass. Comput. Mach. 14, $176-190$.

Hampson R. F., Jr. and Garvin D. (Editors) (1978) Reaction rate and photochemical data for atmospheric chemistry 1977. NBS Special Publication 513, U.S. Department of Commerce, Washington, D.C.

Hanst P. L. and Gay B. W. Jr. (1977) Photochemical reactions among formaldehyde, chlorine, and nitrogen dioxide in air Envir. Sci. Technol. 11, 1105-1109.

Keifer W. S. (1977) The generation of ozune in pluntes frun large point sources. Ph.D. Thesis, University of Maryland, College Park, Maryland.

Miller D. F. (1977) Simulations of gas phase $\mathrm{SO}_{2}$ oxidation in power plant plumes. Presented at the $173 \mathrm{rd}$ National ACS Meeting, New Orleans, Louisiana, U.S.A.

Miller D. F., Alkezweeny A. J., Hales J. M. and Lee R. N (1978) Ozone formation related to power plant emissions Science, N.Y. 202, 1186-1188.

Niki H., Maker P. D., Savage C. M. and Breitenbach L. P. (1977) Fourier transform IR spectroscopic observation of pernitric acid formed via $\mathrm{HOO}+\mathrm{NO}_{2} \rightarrow \mathrm{HOONO}_{2}$ Chem. Phys. Lett. 45, 564--566.

Pierrard J. M. (1969) Photochcmical decomposition of lead halides from automobile exhaust. Enir. Sci. Technol. 3 , $48-51$

Ripperton L. A., Decker C. E. and Page W. W. (1965) Effect of sulfur dioxide on photochemical oxidant production. Presented before the Division of Water, Air, and Waste Chemistry at the 150th National ACS Meeting, Atlantic City, New Jersey, U.S.A

Shen C. H. and Springer G. S. (1977) Photochemical particulate formation in cyclohexene-nitrogen dioxide-air mixlures. Atmospheric Environment 11, 683-688.

Shen C. H., Springer G. S. and Stedman D. H. (1977) Photochemical ozone formation in cyclohexene--nitrogen dioxide-air mixtures. Envir. Sci. Technol. 11, 151-158.

Smith J. P. and Urone P. (1974) Static studies of sulfur dioxide reactions: Effects of $\mathrm{NO}_{2}, \mathrm{C}_{3} \mathrm{H}_{6}$, and $\mathrm{H}_{2} \mathrm{O}$. Envir. $\mathrm{Sci}$. Technol. 8, 742-746.

Spence J. W., Edney E. O. and Hanst P. L. (1978) Peroxychloroformyl nitrate: synthesis and thermal stability. Chem. Phys. Lett. 56, $478 \cdots 483$.

Spicer C. W. and Miller D. F. (1976) Nitrogen balance in smog chamber studies. J. Air Pollut. Control Ass. 26, 45-51.

Stedman D. H. and Niki H. (1973) Photolysis of $\mathrm{NO}_{2}$ in air as measurement method for light intensity. Envir. Sci Technol. 7, 735-739.

Stedman D. H., Ay J., Williams J. R. and Adamson T. C. (1974) Afterburning of solid rocket exhaust. Astronaut Acta 1, 1507-1509.

Stephens E. R., Scott W. E., Hanst P. L. and Doerr R. C (1956) Recent developments in the study of the organic chemistry of the atmosphere. J. Air Pollut. C'ontrol Ass. 6, 159-165.

Wallace J. S. (1978) Photochemical ozone and nitric oxide formation in air and nitrogen dioxide mixtures containing sulfur dioxide, chlorine, or hydrogen sulfide. Ph.D. Thesis, University of Michigan, Ann Arbor, Michigan, U.S.A.

Wang C. C., Davis L. I., Jr., Wu C. H., Hapar S., Niki H. and Weinstock B. (1975) Hydroxyl radical concentrations measured in ambient air. Science, N.Y. 189, 797-800

Watson R. T. (1977) Rate constants for reactions of $\mathrm{ClO}_{x}$ of atmospheric interest. J. Phys. Chem. Ref. Data 6, 871.918 Wilson W. E. and Levy A. (1970) A study of sulfur dioxide in photochemical smog I. Effect of $\mathrm{SO}_{2}$ and water vapor concentration in the 1-butene $\mathrm{NO}_{x} \mathrm{SO}_{2}$ system. 1. Air Pollut. Control Ass. 20, 385390.

Wilson W. E., Levy A. and Wimmer D. B. (1972) A study of sulfur dioxide in photochemical smog II. Effect of sulfur dioxide on oxidant formation in photochemical smog. $J$. Air Pollut. Control Ass. 22, 27-32.

Wongdontri-Stuper W., Simonatis R. and Heicklen J. (1978) The reaction of $\mathrm{ClOO}$ with NO. Geophys. Res. Letr. 5, 10051008 .

\section{APPENDIX. REACTION VESSEL SURFACE EFFECTS}

Surface effects were first suspected in mixtures containing only nitrogen dioxide and air, since loss of nitrogen dioxide to the walls was apparently occurring. Accordingly, a term representing surface reaction of $\mathrm{NO}_{2}$ was formulated by assuming that the rate of reaction of nitrogen dioxide at the surface was proportional to the instantaneous local nitrogen dioxide concentration and to the exposed surface area. Thus, the $\mathrm{NO}_{2}$ lost due to surface reaction from a volume element of length $\Delta Z$ was expressed as

$\mathrm{NO}_{2}$ concentration

change per unit

time due to

interaction with

$$
=-k_{s}\left[\mathrm{NO}_{2}\right] \frac{2 \pi r \Delta Z}{\pi r^{2} \Delta Z}
$$

the surface

where $\left(\mathrm{NO}_{2}\right)$ is the instantaneous nitrogen dioxide concentration (ppm), $r$ is the inside radius of the reaction vessel (m), and $k_{s}$ is the rate constant for the nitrogen dioxide reaction at the surface $\left(\mathrm{m} \mathrm{min}^{-1}\right)$. The rate constant $k_{s}$ was found to be a function of the mean velocity, and the irradiation time: $k_{\mathrm{s}}=k V^{2} t$. The constant $k$ was estimated as follows. An arbitrary value of $k$ was selected. Using this value and the rate constants given in Table 1 , the conservation equations were solved for the desired initial nitrogen dioxide concentrations and flow rates. The ozone and nitric oxide concentrations thus calculated were compared to the measured concentrations. The value of $k$ was then adjusted until the best fit was found between the calculated and measured concentrations. This procedure was repeated at five different air flow rates $\left(47.2,94.4,188.8,377.7\right.$, and $\left.755.1 \mathrm{~cm}^{3} \mathrm{~s}^{-1}\right)$ with mixtures containing either $1 \mathrm{ppm}$ or $5 \mathrm{ppm}$ nitrogen dioxide. In this manner $k$ was found to be about $5 \times 10^{-4} \mathrm{~m}$

It is likely that a portion of the nitrogen dioxide that reacted at the surface was converted to nitric oxide and released back into the gas mixture. The mechanism by which the conversion from nitrogen dioxide to nitric oxide occurred is not known although surface photolysis is possible. However, the effect was achieved in the model by arbitrarily increasing the rate constant for reaction 4 (which converts nitrogen dioxide to nitric oxide in the gas phase) from $1.37 \times$ $10^{4} \mathrm{ppm}^{-1} \mathrm{~min}^{-1}$ (its known value) to $2.5 \times 10^{4} \mathrm{ppm}^{-1}$ $\min ^{-1}$. This latter value resulted in the best fit to the data and was subsequently used with the mathematical model.

Other products of the nitrogen dioxide surface reaction are not known. Studies by Gay and Bufalini (1971) and Spicer and Miller (1976) indicated that the major product was most likely nitric acid. Since nitric acid does not react at any appreciable rate with any of the species present in the test mixture, it was not included in the reaction mechanism

The validity of the assumptions made here regarding $k_{s}$ and $k_{4}$ were assessed by comparing measured and calculated ozone and nitric oxide concentrations. These comparisons are shown in Fig. 7. The solid curves are the concentrations calculated for gas phase reactions only (Table 1). The data points in these figures were corrected for surface effects as 
discussed below. The excellent agreement between the calculated and measured ozone and nitric oxide concentrations suggest that the method used adequately, although arbitrarily, accounts for the participation of the reaction surface in the reaction model.

The measured ozone and nitric oxide concentrations were corrected for losses on the surface of the reaction vessel in the following manner. First, the conservation equations corresponding to the appropriate reaction mechanism were solved. Second, a term representing the loss of $\mathrm{NO}_{2}$ was included into the conservation equation for $\mathrm{NO}_{2}$ and the conservation equations were solved again. The differences between the ozone concentrations given by the two solutions were added to the measured ozone concentrations at the appropriate irradiation time. The measured nitric oxide concentrations were adjusted in the same manner. The corrections thus applied change the measured values of the ozone and nitric oxide concentrations by $10-30 \%$ depending on the circumstances, but do not alter any predicted trends. The sulfur dioxide data were corrected for $\mathrm{NO}_{2}$ losses on the surface in the same manner as for nitrogen dioxide-air mixtures. In chlorine-nitrogen dioxide-air mixtures the surface effects were also evaluated with the assumption that only nitrogen dioxide was lost at the surface. The effects of surface reactions involving chlorine were neglected, because it was found that when the chlorine flow was stopped the measured concentrations of ozone and nitric oxide returned within one residence time to the values obtained before the introduction of the chlorine. This observation suggested that chlorine did not significantly alter the surface. Therefore, only the term for the loss of nitrogen dioxide (Equation A.1) was included in the solution of the conservation equations formulated for the species in Table 3. It is interesting to note that the measured ozone and nitric oxide concentrations would not have changed appreciably, had the value of $k_{\mathrm{s}}$ been affected slightly by chlorine reactions. Solutions of the conservation equations for chlorine-nitrogen dioxide-air mixtures showed that a $10 \%$ change in $k_{s}$ resulted in only a $2 \%$ change in the ozone concentration and a $5 \%$ change in the nitric oxide concentration after 4 mins of irradiation. 